\title{
THE STRUCTURE OF SUBJECTIVE WELL-BEING IN NINE WESTERN SOCIETIES*
}

\begin{abstract}
The structure of subjective well-being is analyzed by multidimensional mapping of evaluations of life concerns. For example, one finds that evaluations of Income are close to (i.e., relatively strongly related to) evaluations of Standard of living, but remote from (weakly related to) evaluations of Health. These structures show how evaluations of life components fit together and hence illuminate the psychological meaning of life quality. They can be useful for determining the breadth of coverage and degree of redundancy of social indicators of perceived well-being. Analyzed here are data from representative sample surveys in Belgium, Denmark, France, Germany, Great Britain, Ireland, Italy, Netherlands, and the United States (each $N \approx 1000$ ). Eleven life concerns are considered, including Income, Housing, Job, Health, Leisure, Neighborhood, Transportation, and Relations with other people. It is found that structures in all of these countries have a basic similarity and that the European countries tend to be more similar to one another than they are to USA. These results suggest that comparative research on subjective well-being is feasible within this group of nations.
\end{abstract}

\section{INTRODUCTION}

Interest in social indicators of life quality, including citizens' perceptions of their own well-being, has inspired a number of sample surveys in recent years. ${ }^{1}$ Such surveys, particularly when done on a comparative and repetitive crossnational basis, have enormous potential for providing information about changing levels of social and economic development and about the processes and conditions that lead to or are associated with the 'good life'. However, the feasibility and usefulness of comparative research in this area - as in any area - are contingent upon the identification of an underlying phenomenon that is in fact comparable from one society to another. While a person's sense of happiness, satisfaction, etc. is of acknowledged importance, the crosscultural comparability of the phenomenon of perceived well-being is largely unexplored. This paper reports an initial, and necessarily incomplete, examination of the comparability of psychological structures of subjective well-being in nine western societies.

This Introduction develops the conceptual framework for the analysis that follows, and describes some of the interests that motivate this presentation. Section 2, Data, describes the sample surveys from which reasonably comparable data from nine nations have been extracted and details the items 
and response scales used to measure perceived well-being. The section on analysis methods discusses the statistical techniques by which we identified the structures of perceived well-being and assessed their similarity across countries. There follows the main substantive results - first for USA and then for eight European nations. The final section of the paper provides some general conclusions, some cautions about interpretation, and some suggestions for further investigation of the issues.

Research on perceived well-being commonly distinguishes between evaluations of life-as-a-whole (sometimes referred to as general or global evaluations) and evaluations of specific life concerns, such as housing, job, relations with other people, safety, or fairness. When we refer to the "structure of subjective well-being" we refer to the way specific life concerns, and evaluations of them, fit together in people's thinking. For example, we ourselves have shown that among American adults evaluations of one's marriage are - quite reasonably - strongly related to evaluations of one's spouse, that evaluations of national political leaders are strongly related to evaluations of government economic programs, but that evaluations of the first pair are virtually independent of evaluations of the second pair. These statistical results suggest that Marriage and National government are distinct life concerns for most Americans. When one combines these results with numerous others, some of which will be described later in this paper, one can identify a psychological structure, or 'cognitive map', from which one can infer the relative positions of life concerns as they are perceived by a particular group of people.

Such structures are interesting for a number of reasons. In showing how well-being perceptions are organized in people's thinking, they indicate some fundamental aspects of what evaluations of life quality mean to these people. Such structures help to identify the distinct well-being concerns that particular groups have, and show the extent that evaluations of these different concerns overlap or intersect with one another. This suggests one of the important practical uses of such structures: They provide guides to the adequacy of coverage and statistical efficiency of indicators of perceived well-being. To the extent that people in different societies organize their thinking about well-being in basically similar ways, it is feasible and potentially productive to undertake cross-cultural research with standardized instruments and to make well-grounded comparative statements based on the results. However, if the basic phenomenon that is being investigated - well-being perceptions shows markedly different structures in different societies, measurements and 
interpretations must be society-specific and any comparative statements must be advanced with extreme caution. ${ }^{2}$

The main substantive purpose of this paper is (a) to explore the structural similarity of well-being perceptions in nine western societies. In so doing, we shall have the opportunity to pursue two other matters of more didactic interest. (b) Our analysis is based on a set of national sample surveys that offer rich opportunities for secondary analysis, and our use of these data may increase analysts' awareness of their existence and accessibility. (c) This analysis involves use of some relatively new statistical methods for assessing similarities among configurations (i.e., structures) and illustrates the need for some further statistical developments; perhaps it will encourage statisticians to pursue these developments.

Before proceeding further, the reader should be cautioned that the analysis reported here is of a rather exploratory nature. The issue of crosscultural similarities in structures of perceived well-being is a fundamental one for those interested in comparative research or in social policies, but the data requirements for a fully adequate investigation are immense. While the data at our disposal are unusually extensive, they are not ideal, and they cannot provide a definitive estimate of the degree of cross-cultural similarity of structures. As will be seen, however, our results do suggest that the similarities may be substantial, and in so doing they suggest that further investigations along this line seem promising.

\section{DATA}

The data analyzed here come from representative national surveys of the noninstitutionalized adult populations in the following nine countries: USA, France, Great Britain, Germany, Italy, Netherlands, Belgium, Denmark, and Ireland. The American data are those of Andrews and Withey (1976) and were collected in May $1972 .{ }^{3}$ The European data come from a series of parallel surveys conducted by the European Economic Community and were collected in each of the EEC countries in May $1976 .{ }^{4}$ The American survey includes 1297 respondents; each of the eight national European surveys includes approximately 1000 respondents (range 923 to 1047). All of the surveys were conducted by personal interviews using professional field staffs and methods such as to suggest that the data include no unusual quality problems. Interviews were conducted in the native language of the respondents. 
In the American survey more than 60 questions asking for evaluations of various life concerns were answered by the respondents. The European data include fifteen such items, of which 11 are reasonably similar to those in the

\section{EXHIBIT 1}

Items Used to Assess Evaluations of Life Concerns in American and European Surveys

\begin{tabular}{|c|c|c|}
\hline Reference & American wording & European wording \\
\hline (Lead in) & $\begin{array}{l}\text { In the next section of this inter- } \\
\text { view we want to find out how } \\
\text { you feel about parts of your } \\
\text { life and life in this country as } \\
\text { you see it. Please tell me the } \\
\text { feelings you have now - taking } \\
\text { into account what has hap- } \\
\text { pened in the last year and } \\
\text { what you expect in the near } \\
\text { future. }\end{array}$ & $\begin{array}{l}\text { Now I would like you to } \\
\text { indicate on this scale to what } \\
\text { extent you are satisfied with } \\
\text { your present situation in the } \\
\text { following respects... }\end{array}$ \\
\hline house & Your house/apartment & $\begin{array}{l}\text { The house, flat or apartment } \\
\text { where you live }\end{array}$ \\
\hline neigh & $\begin{array}{l}\text { This particular neighbor- } \\
\text { hood as a place to live }\end{array}$ & $\begin{array}{l}\text { The part of the town or village } \\
\text { you live in }\end{array}$ \\
\hline income & $\begin{array}{l}\text { The income you (and } \\
\text { your family) have }\end{array}$ & $\begin{array}{l}\text { The income of you and your } \\
\text { family }\end{array}$ \\
\hline std lvg & $\begin{array}{l}\text { Your standard of living - } \\
\text { the things you have like } \\
\text { housing, car, furniture, } \\
\text { recreation and the like }\end{array}$ & $\begin{array}{l}\text { Your standard of living; the } \\
\text { things you have like furniture, } \\
\text { household equipment, and so } \\
\text { on }\end{array}$ \\
\hline job & Your job & $\begin{array}{l}\text { Your present work - in your } \\
\text { job or as a housewife }\end{array}$ \\
\hline spare time & $\begin{array}{l}\text { The way you spend your } \\
\text { spare time, your non- } \\
\text { working activities }\end{array}$ & $\begin{array}{l}\text { The way you spend your spare } \\
\text { time }\end{array}$ \\
\hline trnspt & $\begin{array}{l}\text { The way you can get around } \\
\text { to work, schools, shopping, } \\
\text { etc. }\end{array}$ & $\begin{array}{l}\text { Your means of transport - } \\
\text { the way you can get to work, } \\
\text { schools, shopping, etc. }\end{array}$ \\
\hline health & $\begin{array}{l}\text { Your own health and } \\
\text { physical condition }\end{array}$ & Your present state of health \\
\hline time & $\begin{array}{l}\text { The amount of time you } \\
\text { have for doing the things } \\
\text { you want to do }\end{array}$ & $\begin{array}{l}\text { The amount of time you have } \\
\text { for doing the things you want } \\
\text { to do }\end{array}$ \\
\hline treated & $\begin{array}{l}\text { The way other people } \\
\text { treat you }\end{array}$ & The respect people give you \\
\hline get on w peop & $\begin{array}{l}\text { How you get on with other } \\
\text { people }\end{array}$ & $\begin{array}{l}\text { In general terms, your relations } \\
\text { with other people }\end{array}$ \\
\hline
\end{tabular}


American data. Exhibit 1 presents the exact wording of these 11 items as presented to the American respondents and to English-speaking European respondents.

The American respondents recorded their feelings about these life concerns along a seven-point scale that ranged from 'Delighted' to 'Terrible,' or in one of several off-scale categories: 'Neutral (neither satisfied nor dissatisfied),' 'I never thought about it,' or 'Does not apply to me.' The European ratings were along an eleven-point scale of satisfaction that ranged from 'Completely dissatisfied' to 'Very satisfied.' While the 7-point DelightedTerrible and 11-point Satisfaction scales are not identical, previous research suggests that the substantive differences between them are likely to be rather small and that both offer effective means of measuring evaluations of life concerns (see Andrews \& Withey, 1976, Chapters 3 and 6).

\section{ANALYSIS METHODS}

Our interests required the performance of two distinct analytic tasks: (a) identification of the structure of well-being assessments in each country and (b) determination of the similarities among these structures.

The structures were identified using Smallest Space Analysis, ${ }^{6}$ one of the several forms of non-metric multidimensional scaling (Guttman, 1968; Shepard, Romney, and Nerlove, 1972). Within each country, associations (product-moment $r$ 's) between each pair of the well-being assessments were determined, and the resulting matrix of intercorrelations was used as input to Smallest Space Analysis. Smallest Space Analysis then iteratively approaches that configuration of points (i.e., of life concern assessments) in multidimensional space which maximizes the similaraties of rank orderings of the distances between the pairs of points and the associations (correlations) between the respective life concern assessments. Thus, assessments that show strong positive associations with one another, suggesting that they tap the same life concern or highly related ones, are placed close to one another, and assessments that are statistically independent are placed far apart. Of course, given a large number of life concern assessments, there is no necessity that a perfect consistency can be achieved between the distances of the points in a small-dimensioned space and the sizes of the associations among the assessments; however several statistics are available for measuring this consistency. ${ }^{7}$

In the present analysis, structures of subjective well-being were identified 
by using all of the available well-being assessments - more than 60 assessments in the American data and all 15 items in the European data. Although only 11 assessments were similar between the American and European surveys, the placement of these 11 within each national structure could be more accurately determined within the context of a larger set of items than if only the associations among these 11 had been considered. After trial fittings in spaces of several different dimensionalities, it was determined that a three-dimensional space permitted an adequate portrayal of the structures. ${ }^{8}$

The second major analysis task was to determine the similarity between the various national structures, represented by the three-dimensional configurations of 11 items, as extracted from the larger structures. The rigid ('procrustean') approach proposed by Schönemann and Carroll (1970) was used to match the configurations, and then the degree of match was measured by the Lingoes-Schönemann S statistic (Lingoes and Schönemann, 1974). ${ }^{9}$

The technique of matching involves taking one configuration as the 'target' and then rotating, moving, and contracting or dilating another configuration so as to get the corresponding points in each configuration to match one another as closely as possible. Note that the right $\left(90^{\circ}\right)$ angles between the axes are kept rigid and that none of these several transformations changes the relative distances among the pairs of points within either of the configurations; the transformations merely serve to remove inconsequential differences in the original locations, orientations, and sizes of the configurations.

The Lingoes-Schönemann S statistic has two characteristics that make it well suited for assessing configurational similarities in our analysis: (a) It is a symmetric statistic - i.e., it has the same value regardless of which configuration is used as the target. (b) It is scale-invariant - i.e., the value of the statistic does not depend on the 'size' of the configurations. These two characteristics are particularly desirable in the present analysis, where our desire to measure the similarity among all possible pairs of nine configurations makes it impossible to use the same target for all comparisons.

Since the $S$ statistic is not yet well known, it may be helpful to comment on its interpretation. Lingoes and Schönemann (1974, page 426) note that $S^{1 / 2}$ is the matrix analogue of a coefficient of alienation $\left(=\left(1-r^{2}\right)^{1 / 2}\right)$. Thus low $S$ values imply high similarity (low alienation) and high values imply low similarity. For example, an $S^{1 / 2}=1.0$ implies a zero product-moment correlation between the dimensional locations of the points in the two configura- 
tions, and an $S^{1 / 2}=0.0$ implies a perfect match (product-moment $r=1.00$ ). As will be seen in the following section, values of $S^{1 / 2}$ of $0.5,0.6$, or 0.7 were typical for the configurations matched here, and these values of $S^{1 / 2}$ correspond to product-moment correlations between the dimensional locations of 0.87 , 0.80 , and 0.71 , respectively.

So far as we are aware, there have not been, as yet, any statistical tests developed for the $S$ statistic, ${ }^{10}$ nor any explorations of how $S$ is afffected by various types of measurement errors in the variables that define the configurations. With respect to tests of $S$, it seems likely that the Schönemann Carroll transformations, which take advantage of whatever matchings that exist between two configurations, would act to decrease the expected value of $S$ (e.g., pairs of perfectly random configurations would probably show mean values of $S$ below the theoretical $S$ value of 1.00). On the other hand, the impact of measurement errors on the variables probably acts to increase the value of $S$ (e.g., two identical latent configurations, each represented by data containing different measurement errors, would probably not generate the theoretical $S=0$ ). It is virtually certain that both of these effects have influenced the $S$ values reported in the next section, ${ }^{11}$ but the extent to which the two effects may have canceled each other is unknown.

\section{RESULTS}

It will be most convenient to begin the presentation of results with the configuration for the $60+$ life concern evaluations by the American respondents and to note how the 11 items that are similar to those in the European data fit within this larger structure. Following this, we shall examine similarities in the structure for all possible pairs of countries. Finally, we present plots of the structures in selected European nations and of a derived combined configuration for all eight European nations, and compare these structures to that for the USA.

\section{Structure for USA}

Exhibit 2 shows the three-dimensional structure for evaluations of 63 life concerns by American respondents and indicates the 11 items from this set that are similar to those used in the European surveys. Several things are worth noting. 

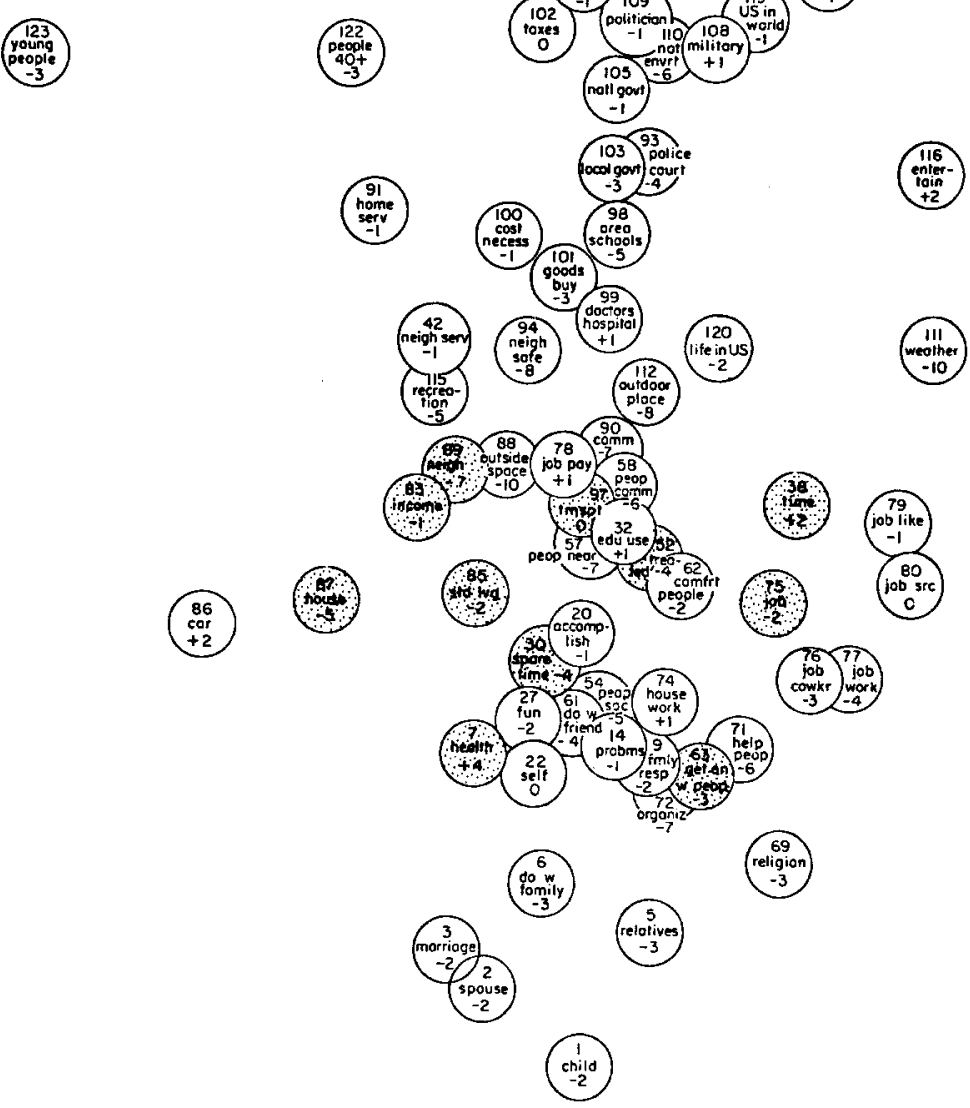

EXHIBIT 2. Three-dimensional structure of evaluations of 63 life concern items by American respondents.

Notes: Stippled items are those for which similar items exist in European surveys. Signed numbers indicate position on the third dimension. Data source: 1297 respondents to 1972 American national survey. Based on Exhibit 2.4 of Andrews and Withey (1976). For exact wording of all items see Exhibit 2.1 of Andrews and Withey (1976); wording of stippled items appears in Exhibit 1 of the present paper.

(a) One dimension, shown vertically in the exhibit, seems to array items according to the psychological immediacy of the life concern. The dimension ranges from items tapping family concerns (near the bottom of the exhibit), through items tapping concerns about one's relations with the immediate external environment - job, neighborhood, relations with other people, etc. 
(in the middle of the exhibit), to items tapping concerns about the larger society - national government, mass media, etc. (near the top). ${ }^{12}$

(b) Items that, on the basis of their content, would seem to tap the same life concern do in fact tend to cluster together and thereby serve to locate the nature and approximate postion of the underlying concern. For example, note the cluster of job items at the right side of the exhibit, the cluster of family items at the bottom, the cluster of government items at the top, and many others. ${ }^{13}$

(c) The 11 items that are similar to items in the European data (stippled in Exhibit 2) represent a rather limited middle segment of the total structure identified for American respondents. The European data contain no items that are similar to items at the extremes of the vertical (the psychological immediacy) dimension: There are no items at all that tap concerns about marriage or family, and those that tap more remote societal concerns were substantially different from those used in the American survey. Thus what appears to be a major dimension of the American structure will be, of necessity, rather attenuated in the structural matches that follow.

(d) Despite the restricted structural differentiation of the 11 items that are similar to those in the European surveys, a careful examination shows some interesting locational differences. We shall pause to detail them here so that later we can compare them with the European structures. With respect to the first two dimensions of the exhibit (the vertical and horizontal dimensions), one can see that the more personally immediate items - assessments of health, of one's relations with other people, of how one spends one's spare time, and of the amount of time available - are in the lower or right-hand portions of the structure, while items assessing more psychologically remote economic or physical concerns - housing, neighborhood, income, standard of living, and transportation - are in the upper-left portion of the structure. On the third dimension (which runs from 'in front of' to 'in back of' the plane of the exhibit), the housing and neighborhood items are well 'back,' the income and standard of living items, the two items tapping relations with other people, and the spare time item are modestly 'back,' and the health item is somewhat in 'front'.

\section{Similarity Among Nine Countries}

Having examined the structure of subjective well-being assessments in some detail as derived for American respondents, we can now ask how similar it 
is to comparable structures for respondents in eight European countries. We can also ask how similar the European structures are to one another. Some initial answers appear in Exhibit 3, which presents values of $S^{1 / 2}$ for all possible comparisons among the nine countries. ${ }^{14}$ Also shown in Exhibit 3 is the similarity of each national structure to a derived structure which represents the single best-fit approximation to the eight individual European structures.

\section{EXHIBIT 3}

Degree of dissimilarity between structures of life concern assessments in nine countries

\begin{tabular}{lllllllllll}
\hline & USA & FRA & GB & GER & ITA & NLD & BEL & DEN & IRE & (EC) \\
\hline United States & - & & & & & & & & & \\
France & 0.77 & - & & & & & & & & \\
Great Britain & 0.78 & 0.44 & - & & & & & & & \\
W. Germany & 0.71 & 0.74 & 0.66 & - & & & & & & \\
Italy & 0.70 & 0.66 & 0.67 & 0.72 & - & & & & & \\
Netherlands & 0.64 & 0.70 & 0.64 & 0.72 & 0.72 & - & & & & \\
Belgium & 0.75 & 0.52 & 0.56 & 0.73 & 0.81 & 0.63 & - & & & \\
Denmark & 0.77 & 0.68 & 0.63 & 0.73 & 0.75 & 0.46 & 0.55 & - & & \\
Ireland & 0.65 & 0.69 & 0.56 & 0.54 & 0.56 & 0.58 & 0.76 & 0.72 & - & \\
\hline (European centroid) 0.65 & 0.61 & 0.57 & 0.67 & 0.68 & 0.62 & 0.64 & 0.63 & 0.61 & - \\
\hline
\end{tabular}

Notes: The measure of dissimilarity is $S^{1 / 2}$, a matrix alienation coefficient (Lingoes and Schönemann, 1974). Low values of $S^{1 / 2}$ indicate high configurational similarity.

The left-most column of the exhibit shows how the USA structure (of 11 items, as contained within the larger set of 63 items shown in Exhibit 2) matches each of the European national structures (of 11 items as contained within their own larger sets of 15). One can see that the coefficients vary only modestly - from 0.64 to 0.78 . This suggests that Americans' structure of well-being perceptions is about as similar to the structure of one European country as it is to another. Within the limited range of the differences, however, the American structure is most similar to that of The Netherlands, closely followed by Ireland, and least similar to the structures in Great Britain, France, and Denmark.

The fact that the British structure is least similar to the American has interesting implications: It suggests that the cross-national differences we 
observe do not reflect artifacts of translation, for the wording of the British and American items was closely similar (in some cases identical), yet the differences between the American and British structures are greater than those between the American pattern and that resulting from questions posed in German, French, Dutch, Danish or Italian.

Probably more important than these modest differences, however, is the absolute level of the coefficients in the left-most column of the exhibit. With values approximating 0.7 (which, as noted in Section 3 of this paper, correspond to product moment $r$ 's of about 0.7 ), the data suggest a rather substantial configurational similarity between structures of well being assessments in the United States and these European countries.

The value of 0.65 shown for the match between the American configuration and the European centroid configuration is also of interest. This figure suggests that the European average is somewhat closer to the USA structure than are most of the individual European countries. Thus while the European average structure is certainly not identical to the American structure, as the individual European national structures deviate away from their own average, they also tend to deviate away from the American structure rather than toward it. Or in still other terms, the American structure has (slightly) more in common with Europe-as-a-whole than with most of the individual European structures.

Exhibit 3 also provides interesting results on the similarities among the various European structures themselves. Here the coefficients vary from 0.44 , for Great Britain and France (which are most similar to one another), to 0.81, for Belgium and Italy (which are least similar). Furthermore, if one computes some averages based on the data in Exhibit 3 one finds that of all the individual national structures, the British structure is most typical of the European structures (mean $S^{1 / 2}=0.59$ ) and the Italian structures is most distinctive (mean $S^{1 / 2}=0.70$ ). The same results can be seen in Exhibit 3 by comparing the individual European structures to the European centroid.

To summarize these various findings from Exhibit 3 we can observe that: (a) there seems to be a basic similarity in structures among all nine of these western societies; (b) within this basic similarity the European structures are distinct from the American structure; (c) even within Europe there is modest heterogeneity; and (d) if one averages out the differences among the individual European structures, the result is a structure that is closer to the American structure than are most of the individual European structures. ${ }^{15}$ 


\section{Structures for EEC Countries}

What are the European structures? Lack of space precludes a presentation of each one, but Exhibits 4 and 5 present the structures for the Netherlands and Great Britain, respectively. ${ }^{16}$ The Dutch structure was selected because it is the individual structure most similar to the American one; and the British structure because, while still basically similar, it matches the USA least well.

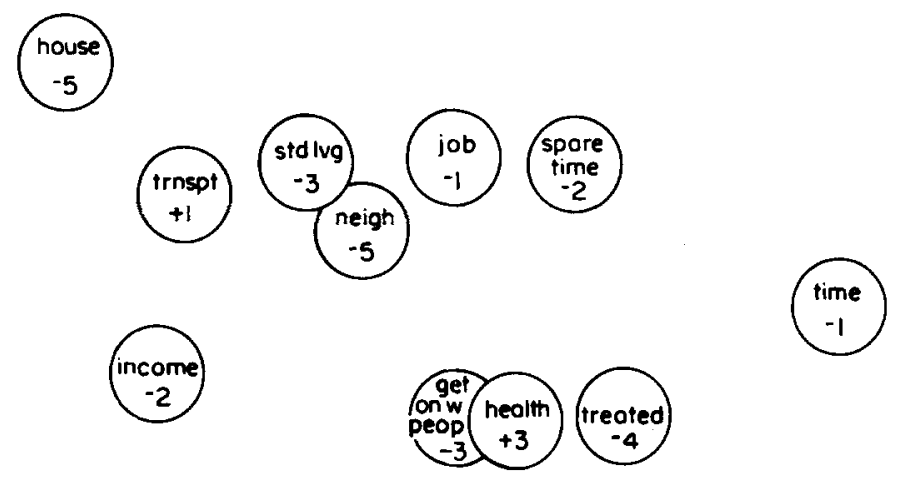

EXHIBIT 4. Three-dimensional structure of evaluations of 11 life concern items by Dutch respondents.

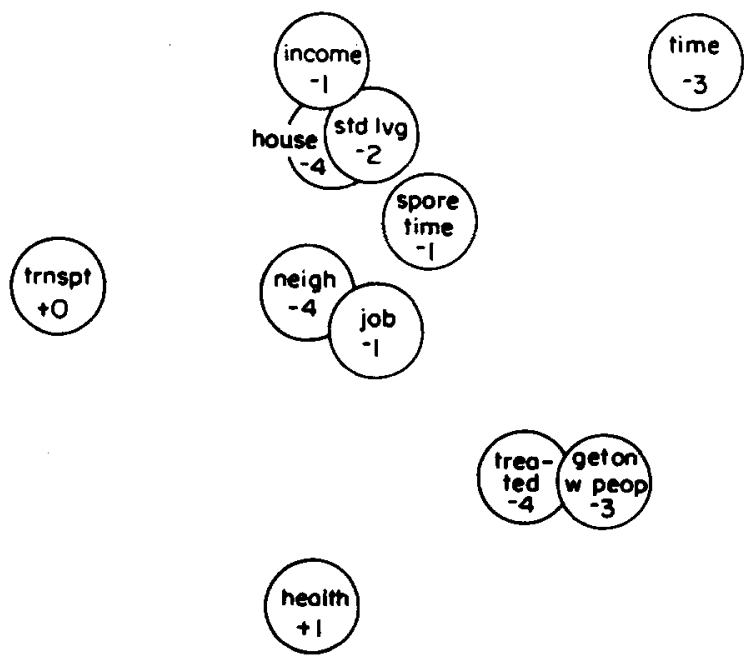

EXHIBIT 5. Three-dimensional structure of evaluations of 11 life concern items by British respondents. 
As presented in Exhibits 4 and 5, the Dutch and British structures are oriented to agree with the presentation of the American structure in Exhibit 2.

In the case of both the Dutch and British structures one can see the same basic pattern among these 11 items that was identified previously in our discussion of the American structure. Note that all the personally immediate items (health, relations with other people, spare time activities and amount of time available) are located in the lower or right-hand portions of the structures, while the more psychologically remote economic or physical concerns fall in the upper left portions. Note also that, comparable with the American structure, housing and neighborhood are both well 'back' on the third dimension, that the two items that tap relations with other people, the income and standard of living items, and the spare time item are modestly 'back,' and that the health item is somewhat in 'front' of the plane of the exhibit. ${ }^{17}$

Another view of the similarities and differences between the American and European structures is presented in Exhibit 6. Plotted there is the United States structure (reproduced from Exhibit 2 and shown by the $U \mathrm{~s}$ ) and also

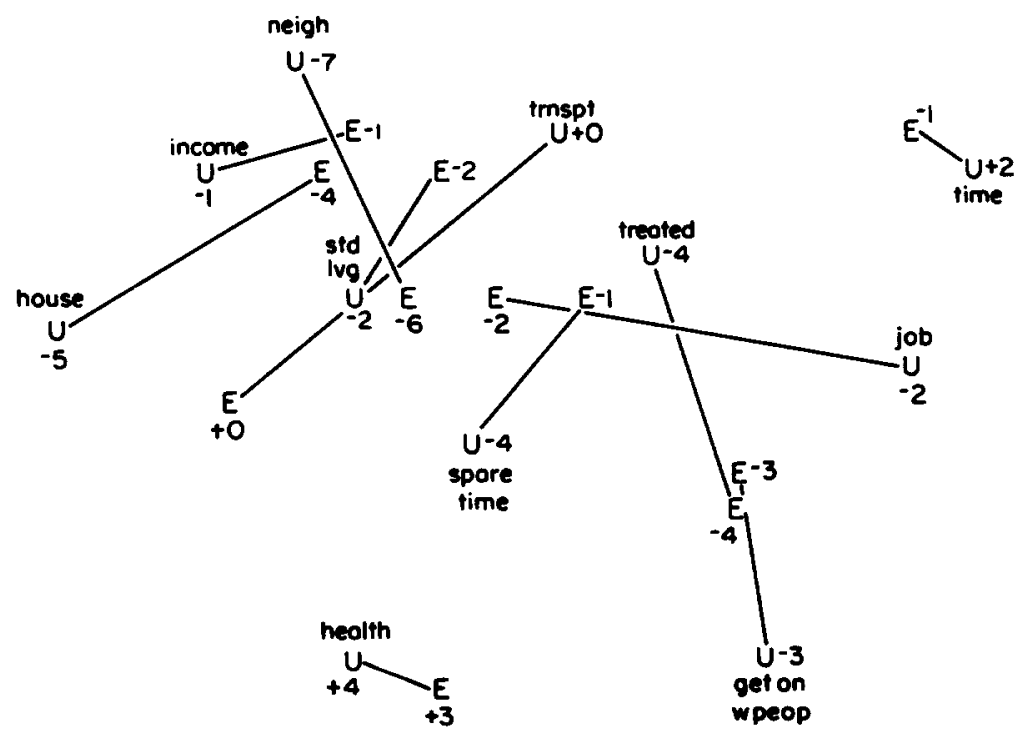

EXHIBIT 6. Match between three-dimensional structures of evaluations of life concern items by American and European respondents.

Key: $\mathrm{U}=$ location in United States structure $\mathrm{E}=$ location in European centroid structure. 
the best-fit average European structure (the European centroid configuration that was discussed previously and for which similarity measures were presented in Exhibit 3 - shown by the $E$ 's).

The basic similarity of the two configurations in the first two dimensions is indicated by the fact that most of the linkage lines are relatively short, and in the third dimension by the close similarity in values of the signed numbers.

With this exhibit it is easy to identify the modest differences that do exist. In the European centroid configuration, compared to the United States structure: the two items tapping relations with other people are much closer together; the job item is much closer to assessments of income and standard of living; and the transportation item moves out to a less central position while income, housing, and neighborhood evaluations move into more central positions. While one might speculate about the inter-cultural causes of these discrepancies, we feel such speculation is best avoided for the present. These differences may be at least partly real, but they are almost certainly at least partly the result of various methodological artifacts. ${ }^{18} \mathrm{We}$ believe that what is most important is the basic similarity of the structures.

\section{COMMENTS AND CONCLUSIONS}

The basic similarities between the structures of well-being assessments across the nine western societies examined here is, we believe, an important finding for the social indicators movement. It suggests that it is feasible to do crossnational comparative research - at least in these countries - on the topic of perceived well-being and that meaningful comparable results can be expected from the use of standardized survey instruments and methods. Only if people in different societies think about well-being in basically similar ways would this be the case, and the initial explorations reported here suggest that in fact they do.

The limited nature of the present explorations, and hence the tentativeness of the conclusions, must be recognized. The number of well-being assessments that were reasonably similar across the national surveys at our disposal was only eleven, and it happens that these eleven items represent only a portion of what previous research suggests is the larger structure. In addition, this analysis is limited by certain methodological factors, including differences in the times at which the American and European surveys were conducted (1972 versus 1976), differences in the response scales used by the two sets of respondents (7-point Delighted-Terrible versus 11-point Satisfaction) and 
differences in the wording and linguistic translations of the items. Some of these differences are endemic to any cross-national research and will always compete with the hypothesis that observed differences are attributable to cultural effects, but even within the limits of what is feasible in current crosscultural research, one could design data better suited to address the issue of structural similarity.

Besides the restrictive nature of the data at our disposal, the definitiveness of the results is limited by the lack of statistics for testing the significance of similarities between configurations and the limitations of knowledge regarding how various types of measurement errors affect measures of configurational similarity.

Assuming that these data and statistical limitations may some day be removed, we would propose some promising extensions of this line of research. (a).Of course, we would wish to extend the descriptive data about similarity of structures beyond the nine western countries examined so far. Would other western countries show similar patterns? What about well-being perceptions in non-western countries? (b) To the extent that significant differences in structures of well-being assessments were identified, one would want to move beyond the descriptive phase and begin to ask what accounts for the structural differences and what impact they have on the behavior of people, governments, etc. Even within the range of the modest differences noted among the nine western societies investigated here, there are hints that similarity varies directly with geographical contiguity, with the comparability of the socioeconomic systems, and/or with the general level of well-being. ${ }^{19}$ Any conclusions along these lines, however, must be extremely tenuous with the present data and would have to be checked against results for a wider range of societies. (c) We have in this paper identified national structures (plus one regional structure - the European centroid configuration). While national structures are conceptually convenient and have an obvious interest, it is possible that other groups of persons should be considered. One can imagine cross-national groupings based on characteristics such as age, sex, occupation, socioeconomic status, cultural group, language, and others. (One can also imagine performing the analysis on certain sub-divisions within a given national grouping, but the research on this topic to data suggests that structural differences are modest. ${ }^{20}$ )

Institute for Social Research University of Michigan 


\section{NOTES}

* Prepared initially for presentation at the 1977 Annual Meeting of the American Statistical Association, Chicago, August 1977. We are grateful to Kai Hildebrant for his skillful processing of data for this paper and for many useful suggestions regarding the analysis. Ed Schneider and James Lingoes also provided helpful advice.

1 See, for example, Abrams (1974); Allardt (1975); Andrews \& Withey (1976); Campbell, Converse, and Rodgers (1976); Development Academy of the Philippines (1975); Hall (1976), Inglehart (1977); Rabier (1974); and Riffault and Rabier (1977).

2 Structural similarity does not, of course, imply that all societies will be similarly satisfied - either in general or with respect to specific life concerns; rather, it means that the relationships among the well-being assessments will be similar.

${ }^{3}$ Collection of these American data was supported by grant GS3322 from the National Science Foundation. These data, together with four other sets of survey data on perceptions of well-being collected under the direction of Andrews and Withey, are available from the Social Science Archive of The Institute for Social Research, The University of Michigan, Ann Arbor, Michigan and also from the Inter-University Consortium for Political and Social Research.

4 These European data are extracted from the May 1976 Euro-Barometer, a series of national surveys conducted semi-annually in the EEC countries and coordinated by the Commission of the European Community. For more details on these surveys and a report of results from earlier Euro-Barometers, see Inglehart (1977), Rabier (1974), and Riffault and Rabier (1977). These and other data from the series are available from the Belgian Archives for the Social Sciences, Catholic University, Louvain, and also from the Inter-University Consortium for Political and Social Research.

5 The off-scale categories were rarely used (with obvious exceptions, such as inquiries about "job"), and were treated as missing data.

6 The technique is implemented in a computer program called MINISSA (Roskam and Lingoes, 1970; Lingoes and Roskam, 1973; Lingoes, Guttman, and Roskam, 1977). Input to MINISSA was a matrix of Pearson correlation coefficients (computed with pairwise deletion of missing data).

7 We have, above, likened the identification of psychological structures to 'cognitive mapping.' This analogy is legitimate: If one submits a matrix of distances between geographic points (e.g., cities) to Smallest Space Analysis, it will produce an acceptable geographic map of the region involved.

Coefficients of alienation, a measure of the consistency between the interpoint distances in the multidimensional space and the intercorrelations among the life concern assessments, ranged from 0.10 to 0.13 for the eight European countries when 15 items were arrayed in three-dimensional space, and was 0.19 for USA when more than 60 items were arrayed in three-dimensional space. Comparable figures for twodimensional space were $0.18-0.21$ for the European countries and 0.26 for USA. When only the 11 items that are similar in the USA and European data were arrayed in three dimensions, the coefficient of alienation for the USA data was 0.10 .

9 Two computer programs were used to accomplish these tasks: PINDIS (Lingoes and Borg, 1976; Lingoes, Guttman, and Roskam, 1977), and SPACES (Computer Support Group of the Center for Political Studies, 1976).

10 Neel, Rothhammer, and Lingoes (1974) report a Monte Carlo exploration of the stability of $S$ in one application but do not provide statistical tests which are of general applicability.

11 From previous analyses (Andrews and Withey, 1976, Chapter 6), we can estimate that the American data used in this paper has validity of about 0.7 , reliability of about 0.8 , and includes about 10 percent correlated measurement error and about 40 percent uncorrelated measurement error. A roughly similar composition is expected to characterize the European data. 
12 The two other dimensions of the space, while needed to loca te items in correct relative position to one another, do not seem to show conceptually meaningful progressions. While such progressions are interesting if found, there is no necessity that they occur, and no requirement that one "interpret" the dimensions of a structure. (Note that the same applies to the 2 - or 3 - dimensions of geographic or celestial maps.)

13 Andrews and Withy (1976, Chapter 3) identify 12 clusters among these items.

14 Values of the square root of $S$ (i.e., of $S^{1 / 2}$ ) rather than of $S$ are presented because it is this statistic that Lingoes and Schönemann (1974) propose as the matrix analogue of a coefficient of alienation (and because these values are produced by the PINDIS and SPACES computer programs used for the present analysis).

15 In an exploration going one step beyond the similarity analyses reported in this subsection, we considered the possible effects of differential weighting of the dimensions of the configurations. (This is another capability of the PINDIS and SPACES computer programs referenced previously.) While differential weighting made it possible to more closely match most of the configurations, the differences were not large and the basic pattern of results just described for Exhibit 3 was maintained. In a related but as yet unpublished analysis, Russell Dalton has examined cross-national similarities in the structure of perceived well-being using 1973 and 1975 European data. His results are in general accord with those reported here and provide an approximate replication from an independent source.

16 Configurations for the other six European countries will be provided upon request.

17 Campbell, Converse, and Rodgers (1976, pg. 74-75) report a matching of American and British structures based on different and somewhat more limited data than those used for Exhibits 2 and 5. While some of the details of their matching differ from what we find here, their general conclusion - that "the correspondence is fairly close" clearly agrees with ours. Levy (1976) has also reported a matching of well-being structures derived from American and Israeli respondents. Here, also, a conclusion of there being a substantial match was also put forward, though a numerical assessment of the degree of fit was not made.

18 These include differences in item wordings (particularly for the job item), in the set of other items that were present when the original structures were determined, and in the error compositions of the measures.

19 For example, we observed a correlation of about 0.3 between the similarity of structures of perceived well-being (shown in Exhibit 3) and the differences between the countries in mean satisfaction with "life in general." Given a more heterogeneous set of countries, this relationship might appear stronger and, if so, might be attributed to the operation of Maslovian principles.

20 Andrews and Withey (1976, Chapter 2) and Campbell, Converse, and Rodgers (1976, Chapter 3 ) both report explorations of differences in such perceptual structures among subgroups of the American population. Both sets of investigators, using entirely independent sets of data, came to the same general conclusion: that while modest differences appeared among structures identified for the subgroups, the basic features of the structure identified at the national level remained evident. Andrews and Withey (1976, Chapter 4) also showed that the same prediction equation was about equally effective for a large number of different subgroups for predicting feelings about general well-being on the basis of evaluations of life concerns.

\section{REFERENCES}

Abrams, M. 'Subjective social indicators'. Social Trends, No. 4. London, Her Majesty's Stationary Office, 1973. 
Allardt, E. 'Dimensions of welfare in a comparative Scandinavian study'. Research Reports No. 9. Helsinki, Research Group for Comparative Sociology, University of Helsinki, 1975.

Andrews, F. M. and Withey, S. B. Social Indicators of Well-being: Americans' Perceptions of Life Quality. New York, Plenum, 1976.

Campbell, A., Converse, P. E., and Rodgers, W. L. The Quality of American Life: Perceptions, Evaluations, and Satisfactions. New York, Russell Sage Foundation, 1976.

Computer Support Group of the Center for Political Studies. SPACES: Program Writeup. Ann Arbor, Michigan, Institute for Social Research, The University of Michigan, June 1976.

Development Academy of the Philippines. Measuring the Quality of Life: Philippine Social Indicators. Manila, Development Academy of the Philippines, 1975.

Guttman, L. 'A general nonmetric technique for finding the smallest coordinate space for a configuration of points'. Psychometrika, 1968, 33, 469-506.

Hall, J. 'Subjective measures of quality of life in Britain: 1971 to 1975; Some developments and trends'. Social Trends, No. 7. London, Her Majesty's Stationary Office, 1976.

Inglehart, R.F. The Silent Revolution: Changing Values and Political Styles among Western Publics. Princeton, Princeton University Press, 1977.

Levy, S. 'Use of the mapping sentence for coordinating theory and research: A cross cultural example'. Quality and Quantity, 1976, 10,117-125.

Lingoes, J. C. and Borg, I. 'Procrustean individual difference scaling'. Journal of Marketing Research, 1976, 13, 406-407.

Lingoes, J. C., Guttman, L., and Roskam, E. E. Geometric Representations of Relational Data. Ann Arbor, Michigan, Mathesis Press, 1977.

Lingoes, J. C. and Roskam, E. 'A mathematical and empirical study of two multidemensional scaling algorithms'. Psychometric Monographs, 1973, 38.

Lingoes, J. C. and Schönemann, P. H. 'Alternative measures of fit for the SchönemannCarrol matrix fitting algorithm'. Psychometrika, 1974, 39, 423-427.

Neel, J. V., Rothhammer, F., and Lingoes, J. C. 'The genetic structure of a tribal population, the Yanomamo Indians. X. Agreement between representations of village distances based on different sets of characteristics'. American Journal of Human Genetics, 1974, 26, 281-303.

Rabier, J. R. Satisfaction et Insatisfaction Quant aux Conditions de Vie dans les Pays Membres de la Communaute Europeene. Brussels, Commission of the European Communities, 1974.

Riffault, H. and Rabier, J. R. The perception of poverty in Europe. Brussels, Commission of the European Communities, 1977.

Roskam, E. and Lingoes, J. C. 'MINISSA-I: A FORTRAN IV (G) program for the smallest space analysis of square symmetric matrices'. Behavioral Science, 1970, 15, 204-205.

Schönemann, P. H. and Carroll, R. M. 'Fitting one matrix to another under choice of a central dilation and a rigid motion'. Psychometrika, 1970, 35, 245-255.

Shepard, R. M., Romney, A. K., and Nerlove, S. B. Multidimensional Scaling. New York, Seminar Press, 1972. 